\title{
An Uncommon Dental Anomaly: Talon Cusp
}

\author{
${ }^{1}$ Usha Hegde, ${ }^{2}$ Paras Mull J, ${ }^{3}$ Gazala Danish, ${ }^{4}$ Syed Nabeel \\ ${ }^{1}$ Consultant, Oral and Maxillofacial Pathologist, Smile Maker Clinics, Mysore, Karnataka, India \\ ${ }^{2}$ Consultant, Endodontist, Smile Maker Clinics, Mysore, Karnataka, India \\ ${ }^{3}$ Consultant, Oral and Maxillofacial Diagnostician and Radiologist, Smile Maker Clinics, Mysore, Karnataka, India \\ ${ }^{4}$ Director, Smile Maker Clinics, Mysore, Karnataka, India
}

Correspondence: Usha Hegde, Consultant, Oral and Maxillofacial Pathologist, Smile Maker Clinics, \#187, 2nd Stage, MG Road 2nd Main, Udayagiri, Mysore-570 019, Karnataka, India, Phone: +919844453444, 9845106626, e-mail: gundheg@yahoo.com dr.syednabeel@gmail.com

\begin{abstract}
Talon cusp is an uncommon dental anomaly presenting as an accessory cusp. It is seen in both deciduous and permanent dentition and on lingual and facial surfaces of anterior teeth. It can occur unilaterally or bilaterally. The incidence of occurrence is more in maxillary teeth. It is usually asymptomatic but can pose functional and esthetic problems. This article presents the review of talon cusp in relation to its definition, etiopathogenesis, prevalence, clinical and histological findings, clinical implications, radiographic findings, classification and management aspects.
\end{abstract}

Keywords: Talon cusp, accessory cusp, dental anomaly.

\section{INTRODUCTION}

Talon cusp was described as an anomalous hyperplasia of the cingulum of maxillary or mandibular permanent incisors resulting in the formation of a supernumerary cusp resembling an eagle's talon. ${ }^{1,2}$ However, there are reports of talon cusp occurring on the facial surfaces, in deciduous incisors and also in canines. Therefore, the talon cusp can now be defined as an uncommon dental anomaly manifesting as an accessory cusp-like structure, projecting from the lingual or facial surface of anterior teeth of either dentition. ${ }^{3}$ It was first described by WH M itchell in 1892, and was named as "Talon cusp" by M ellor and Ripa in 1970. ${ }^{4}$

The etiopathogenesis is multifactorial, and is thought to be polygenetic with some environmental influences. ${ }^{5}$ Clinically it can pose esthetic and functional problems to the patient. ${ }^{6-9} \mathrm{Histologically,} \mathrm{it} \mathrm{is} \mathrm{composed} \mathrm{of} \mathrm{normal}$ enamel and dentin and it may or may not contain pulpal tissue. ${ }^{7}$ Radiographically the talon cusp is usually superimposed over the tooth on which it occurs. ${ }^{2} \mathrm{Hattab}$ et al ${ }^{6}$ have classified talon cusp as true tal on, semital on and trace tal on, based on the degree of formation and extension. The treatment objective of tal on cusp should include preserving pulpal vitality, meeting esthetic and occlusal requirements, establishing caries prevention or eradication in developmental grooves and eliminating tongue irritation. ${ }^{7}$

\section{REVIEW OF LITERATURE}

Talon cusp was described as an anomalous hyperplasia of the cingulum of maxillary or mandibular permanent incisors resulting in the formation of a supernumerary cusp resembling an eagle's talon. ${ }^{1,2}$ How ever, there are reports of talon cusp occurring on the facial surfaces, in deciduous incisors and also on canines. Therefore, the tal on cusp is now defined as an uncommon dental anomaly manifesting as an accessory cusp-like structure, projecting from the lingual or facial surface of anterior teeth, on either dentition. ${ }^{3}$

Talon cusp was first recognized by W H M itchell in 1892, who described an accessory cusp on the lingual surface of an upper central incisor of a woman as "a process of hornlike shape curving from the base downwards to the cutting edge". In 1970 M ellor and R ipa named the accessory cusps as tal on cusp because of its resemblance in shape to an eagle's tal on. ${ }^{4,6}$

$M$ ader ${ }^{10}$ has suggested that the term talon cusp be reserved only for those anomalous cusps that prominently project from the lingual surface of a succedaneous tooth, that are morphologically well-delineated and extend at least half the distance from the cementoenamel junction to the incisal edge. Talon cusp has even been shown in archaeological specimens. Halcrow SE and Tayles $\mathrm{N}^{11}$ have reported a case of talon cusp in a deciduous lateral incisor 
of an infant from prehistoric Southeast A sia which possibly represents the earliest case of tal on cusp recorded. A nother case of talon cusp in a primary lateral incisor in an ancient skeleton of a medieval child has been published by M ays $\mathrm{S} .{ }^{12}$ This report shows that talon cusp existed in B ritish populations, more than 600 years before the first written description.

A s in the case of any other abnormality of tooth shape and size, talon cusp occurs early in odontogenesis during the morphodifferentiation stage. It may occur as a result of outward folding of the inner enamel epithelial cells (precursors of ameloblasts) and a transient focal hyperplasia of the mesenchymal dental papilla (precursors of odontoblasts). ${ }^{8}$ The susceptibility of the lateral incisors to abnormalities could partly be related to compression of the tooth germ of the lateral incisor by the adjacent central incisor and canine, which develop about 7 months earlier than the lateral incisor. Increased localized external pressure on a tooth germ during morphodifferentiation stage may result in either outfolding of the dental lamina as in the case of talon cusp and shoveling or infolding of the lamina as in dens invaginatus. ${ }^{6}$ Sicher and B haskar ${ }^{13}$ have suggested that disturbances during morphodifferentiation such as altered endocrine function might affect the shape and size of a tooth without impairing the function of the ameloblasts and odontoblasts. A nother possible cause of the condition that is discussed is hyperproductivity of the anterior segment of the dental Iamina. Cases of talon cusp associated with gemination, hyperdontia or mesiodens support this hypothesis. ${ }^{14}$ Bilateral distribution of talon cusp in some cases, its association with other dental abnormalities, tal on cusp occurring in family members, twins, offsprings from consanguineous marriages and in some genetic syndromes support genetic etiology of the condition. $5,8,14,15$ However, sporadic occurrences of this abnormality probably are induced by trauma or other localized insults affecting the tooth germ. Therefore control of the complex processes of dental development appears to be multifactorial. It is primarily polygenetic with some environmental influence. ${ }^{5}$

Prevalence of talon cusp is low affecting less than $1 \%$ to approximately $8 \%$ of the population. ${ }^{16,17}$ It has been reported in different ethnic groups. It has been reported in Caucasians, in A frican A mericans and in Mongoloid population. ${ }^{18}$

Sedano et al ${ }^{16}$ in 1989 assessed the prevalence of talon cusp in Mexican children to be $0.06 \%$. Chawla et al ${ }^{17}$ in
1983 reported that $7.7 \%$ of the North Indian children exhibited a tal on cusp. Tal on cusp is also present in Eskimos, A merican Indians and A sians. ${ }^{18,19}$

It has predilection for permanent dentition than deciduous dentition as $75 \%$ of the cases have been reported involving permanent dentition. M ore cases are reported in mal es than in females ( $M$ al es $64 \%$, females $36 \%$ ). It shows a striking predilection for the maxilla over mandible, with $92 \%$ of cases manifesting in the maxillary anterior teeth. ${ }^{6}$ All reported talon cusps in primary teeth affected the maxillary central incisors, while in the permanent dentition maxillary lateral incisor was most frequently involved (67\%), followed by central incisors (24\%) and canines (9\%). ${ }^{6} \mathrm{~A}$ review of English language dental literature published between 1970 and 1995 showed most information to be based on case reports. A Imost $92 \%$ of the taloned teeth were found in the maxilla with $55 \%$ on lateral incisor and $33 \%$ on central incisors. ${ }^{19}$

Histologically talon cusp is composed of normal enamel and dentin, pulpal tissue may be present or absent. It has been suggested that large tal on cusps, especially those that are separated or stand aw ay from the tooth crown are more likely to contain pulp tissue. ${ }^{6,8}$

Talon cusp is not an entirely innocuous defect. It may give rise to complications. It may present a number of problems both to the patient and the clinician. They include compromised esthetics, occlusal interferences, displacement of affected tooth, carious developmental grooves, pulpal necrosis and periapical pathosis, periodontal problems due to excessive occlusal forces, advanced attrition leading to pulp exposure, irritation of the tongue during speech and mastication, interference with tongue space, problems in breastfeeding, accidental cusp fracture and temporomandibular joint pain. In some cases occlusal interference may not be observed, if the patient presents with bimaxillary protrusion and reduced overbite. ${ }^{6-9} \mathrm{U}$ nerupted taloned tooth may be mistaken radiographically for a supernumerary tooth or compound odontomas, leading to unnecessary surgical intervention. ${ }^{4,18}$

Radiographic image of talon cusp is usually superimposed with that of the tooth on which it occurs. Its outl ine is smooth and a layer of normal appearing enamel is usually distinguishable, but pulp horn if present may not be demonstrated. $^{2}$

Typically the cusp looks like a V-shaped structure superimposed over the normal image of the crown. ${ }^{6}$ The 
cusp is usually radiographically apparent before eruption and may suggest the presence of a supernumerary tooth. This possibility can be ruled out by another radiograph made with an altered horizontal angle of projection (tube shift technique). ${ }^{2}$ In many previous publications that have reported the appearance of talon cusp containing a pulpal extension the diagnosis appears to be based on radiographic evaluation in which the tal on cusps were superimposed over the main pulp chamber. ${ }^{6,8,18} \mathrm{~A}$ ccording to $\mathrm{M}$ ader and Kellogg 20 this is a near impossible way to distinguish the existence of a pulpal extension.

There are no definite diagnostic criteria for talon cusp which include all its forms and variants. Gorlin and Goldman ${ }^{21}$ have defined tal on cusp as a very high accessory cusp which may connect with the incisal edge to produce a $\mathrm{T}$ or $\mathrm{V}$ form or if lower in level a $\mathrm{Y}$-shaped crown contour. Davis and B rook ${ }^{22}$ stated that talon cusp may represent the extreme of a continuous variation, progressing from a normal cingulum, to an enlarged cingulum, then to a small accessory cusp, and then to a talon cusp. H attab et al ${ }^{6}$ have suggested a classification system based on the degree of formation and extension:

Type I (Talon/True talon): A morphologically well delineated additional cusp that prominently projects from the palatal surface of a primary or permanent anterior tooth and extends at least half the distance from the cementoenamel junction to the incisal edge.

Type II (Semitalon): A n additional cusp of a millimeter or more but extending less than half the distance from the cementoenamel junction to the incisal edge. It may blend with the palatal surface or stand away from the rest of the crown.

Type III (Trace talon): Enlarged or prominent cingula and their variations i.e., conical, bifid or tubercle like.

R adiographically it may appear typical ly as a V -shaped radiopaque structure, as for true talon and semitalon, or tubercle-like, originating from the cervical third of the root. ${ }^{6}$

There are reports on unusual presentation of tal on cusps. Cases of facial talon cusp, facial and palatal talon cusps, talon cusp co-occuring with dens invaginatus, gemination, supernumerary teeth and fused tooth, have been reported. ${ }^{3,6,18,22-26} \mathrm{~T}$ alon cusps has been found to occur as an isolated dental anomaly or in association with other dental anomalies. Talon cusp has been reported in literature occurring with other dental anomalies like bifid cingulum, tubercle-like cingulum, accentuated marginal ridges, agenesis of teeth, shovel shaped incisors, dens invaginatus, accessory cusps of premolars, prominent cusps of carabelli, ${ }^{6}$ microdont ${ }^{8}$, cingulum hypertrophy. ${ }^{24}$

Talon cusp has also been reported in patients with Sturge-W eber syndrome, M ohr syndrome, Ellis-van creveld syndrome, Rubinstein-Taybi syndrome and incontinentia pigmenti achromians. ${ }^{6,19,23}$

Treatment may differ depending on each case. Small talon cusps are usually asymptomatic, necessitating no treatment. However, large, prominent and separated talon cusps require definitive treatment with respect to esthetics, occlusion, periodontal and carious problems. ${ }^{6}$ It is desirable to evaluate and treat the talon cusp soon after eruption to avoid further clinical problems. ${ }^{3}$ The developmental grooves at the lateral aspects of the anomalous cusps are susceptible to caries. Deep non-carious grooves and fissures should be cleaned of debris and plaque and prophylactically sealed with fissure sealant. If grooves are carious, the lesion should be eradicated and the cavity filled with glass ionomer restorative material. ${ }^{6}$ W here esthetic appearance and occlusal interference are not a problem the concavity between the cusp and tooth surface can be obturated with composite resin. ${ }^{8}$ In case of premature contact and occlusal interference, the anomalous cusp should be reduced. If the treatment needs the removal of a substantial portion of the cusp, then reduction should be gradual and on consecutive visits at 6-8 weeks intervals to allow deposition of reparative dentin and pulp obliteration within the extension. Following each grinding procedure, the tooth surface should be treated with a desensitizing agent, preferably fluoride varnish. ${ }^{6,23}$ This approach appears to be adequate in some cases but cannot be applied predictably in all situations, particularly if the occlusal interference is severe. In these cases, a complete reduction of the cusp is required. This is probably the most common approach, but it requires some form of pulp therapy, like root canal treatment or vital pulp therapy techniques such as partial pul potomy. ${ }^{23,27}$ Partial pulpotomy has a high success rate comparable to root canal treatment, although size of exposure is not related to the success rates of partial pulpotomy. ${ }^{23}$ In cases with immature tooth, complete reduction of the cusp followed by calcium hydroxide pulpotomy can be done. ${ }^{8}$

\section{CONCLUSION}

In conclusion talon cusp is an accessory cusp like structure occurring on lingual or facial surface of deciduous or 
permanent dentition occurring unilaterally or bilaterally in either of the jaws. Although talon cusp may present as an innocuous and asymptomatic structure and noted only on routine dental examination, it may pose functional and/or esthetic problems. Early detection of talon cusp could prevent the complications associated with it. It is important to identify a talon cusp, since it may be useful in recognizing syndromes associated with it.

\section{REFERENCES}

1. Shafer W G, Hine M K, L evy BM . A Textbook of O ral Pathology. 4th ed. Philadel phia: W B Saunders 1983;40-41.

2. Goaz PW, White SC. Oral Radiology. M issouri: CV M osby Company; 1987; 447.

3. Siraci E, Cem Gungor H, Taner B, Cehreli ZC. B uccal and palatal talon cusps with pulp extensions on a supernumerary primary tooth. Dentomaxillofac Radiol 2006;35(6):469-72.

4. Mellor JK, Ripa LW. Talon cusp: A clinically significant anomaly. Oral Surg 1970;29:225-28.

5. Segura JJ, Jimenez-Rubio A. Talon cusp affecting permanent maxillary lateral incisors in 2 family members. Oral Surg Oral Med Oral Pathol Oral Radiol Endod 1999;88(1):90-92.

6. Hattab FN, Y assin OM, al-N imri K S. Tal on cusp in permanent dentition associated with other dental anomalies: Review of literature and reports of seven cases. A SDC J Dent Child 1996;63(5):368-76.

7. Gungor HC, A Itay N, Kaymaz FF. Pulpal tissue in bilateral talon cusps of primary central incisors: Report of a case. Oral Surg Oral M ed Oral Pathol Oral Radiol Endod 2000;89(2):231-35.

8. Hattab FN, Y assin OM, al-Nimri KS. Talon cusp-clinical significance and management: Case reports. Q uintessence Int $1995 ; 26(2): 115-20$.

9. Soares A B, de A raujo JJ, de Sousa SM , V eronezi M C. Bilateral talon cusp: Case report. Quintessence Int 2001;32(4):283-86.

10. M ader CL. Talon cusp. J A m Dent A ssoc 1981;103(2):244-46.

11. Halcrow SE, Tayles N. Talon cusp in a deciduous lateral incisor from prehistoric Southeast A sia. International Journal of Osteoarchaelogy. Published online-19 Nov 2008. http:// www 3.interscience.wiley.com/journal/121519917/abstract. A ccessed on 24th/feb/2010.
12. M ays S. Talon cusp in a primary lateral incisor from a medieval child. Int J Paediatr Dent. 2005;15(1):67-72.

13. Sicher S, B haskar SN. O rban's oral histology and embryology. (7th ed). St Louis: CV M osby Company 1972;17-37.

14. Dumancic J, Kaic Z, Tolj M, Jankovic B. Talon Cusp: A Literature Review and Case Report. Acta Stomatol Croat 2006;40(2):169-74.

15. Segura-Egea JJ, Jimenez-Rubio A, Rios-Santos JV, V elascoOrtega $E$. D ens evaginatus of anterior teeth (tal on cusp): report of five cases. Quintessence Int 2003;34(4):272-77.

16. Sedano HO, Freyre IC, Garza de la Garza M L, et al. Clinical orodental abnormalities in Mexican children. Oral Surg Oral Med Oral Pathol 1989;68(3):300-11.

17. Chawla HS, Tewari A, Gopalakrishnan NS. Talon cusp-A prevalence study. J Indian Soc Pedod Prev Dent 1983;1(1): 28-34.

18. Al-Omari M A, Hattab FN, Darwazeh A M , D ummer PM . C linical problems associated with unusual cases of tal on cusp. Int Endod J 1999;32(3):183-90.

19. Dankner E, Harari D, Rotstein I. Dens evaginatus of anterior teeth. Literature review and radiographic survey of 15,000 teeth. Oral Surg Oral Med Oral Pathol Oral Radiol Endod 1996;81(4):472-75.

20. $M$ ader $C L, K$ ellogg SL. Primary talon cusp. A SDC J Dent Child 1985;52(3):223-26.

21. Gorlin RJ, Goldman HM (Eds). Thoma's oral pathology, 6th edn. CV M osby Co., St Louis, 1970;96.

22. de Sousa SM, Tavano SM, B ramante CM. Unusual case of bilateral tal on cusp associated with dens invaginatus. Int Endod J 1999;32(6):494-98.

23. A bbott PV . Labial and palatal "talon cusps" on the same tooth: A case report. Oral Surg Oral Med Oral Pathol Oral Radiol Endod 1998;85(6):726-30.

24. Gunduz K, A cikgoz A. A n unusual case of talon cusp on a geminated tooth. Braz Dent J 2006;17(4):343-46.

25. Siraci E, Gungor HC, Cehreli ZC. Dens invaginatus and talon cusp co-occuring in a mandibular central incisor: A case report. A SDC J Dent Child (Chic) 2008;75(2):177-88.

26. V ardhan TH, Shanmugam S. Dens evaginatus and dens invaginatus in all maxillary incisors: Report of a case. Quintessence Int, 2010;41(2):105-07.

27. Dinesh Rao B, Hegde S. A talon cusp on fused teeth associated with hypodontia: Report of a unique case. Eur J Dent 2010;4(1):75-80. 